\title{
Optimizing Gear Performance by Alloy Modification of Carburizing Steels
}

\author{
Thomas Tobie ${ }^{1}$, Frank Hippenstiel ${ }^{2}$ and Hardy Mohrbacher ${ }^{3, *}$ \\ 1 FZG-Gear Research Centre, Technical University of Munich, 85748 München, Germany; \\ tobie@fzg.mw.tum.de \\ 2 BGH Edelstahl Siegen GmbH, 57076 Siegen, Germany; frank.hippenstiel@bgh.de \\ 3 NiobelCon bvba, Department of Materials MTM-KU Leuven, 3001 Leuven, Belgium \\ * Correspondence: hm@niobelcon.net; Tel.: +32-3-484-5260
}

Received: 30 August 2017; Accepted: 26 September 2017; Published: 6 October 2017

\begin{abstract}
Both the tooth root and tooth flank load carrying capacity are characteristic parameters that decisively influence gear size, as well as gearbox design. The principal requirements towards all modern gearboxes are to comply with the steadily-increasing power density and to simultaneously offer a high reliability of their components. With increasing gear size, the load stresses at greater material depth increase. Thus, the material and particularly the strength properties also at greater material depth gain more importance. The present paper initially gives an overview of the main failure modes of case carburized gears resulting from material fatigue. Furthermore, the underlying load and stress mechanisms, under particular contemplation of the gear size, will be discussed, as these considerations principally define the required material properties. Subsequently, the principles of newly developed, as well as modified alloy concepts for optimized gear steels with high load carrying capacity are presented. In the experimental work, the load carrying capacity of the tooth root and tooth flank was determined using a pulsator, as well as an FZG back-to-back test rig. The results demonstrate the suitability of these innovative alloy concepts.
\end{abstract}

Keywords: gear steel; gear failure; tooth root fatigue strength; pitting resistance; quench distortion; microalloying; hardenability; toughness; grain coarsening

\section{Introduction}

Gears and gearboxes are used for a wide range of applications. For example, high power wind turbines usually have a gearbox transforming the low speed rotor shaft rotation into the higher rotational speed required by the generator. Approximately 85 percent of today's windmills are equipped with a gearbox. Usually, such gearboxes are designed as one- or two-stage planetary transmissions. These gearboxes have been gradually increasing in size over recent years due to the up-scaling of individual turbine sizes. In combination with this performance growth, the economic and qualitative optimizations of the entire manufacturing chain are of high importance. The gears in wind turbines are sometimes exposed to extremely high loads at the gear flanks and in the tooth root of the gear teeth, for example during sudden changes of wind speed or hard stops. Many failures and breakdowns of wind turbines, accordingly, originated in the gearbox, leading to significant outages and replacement costs. The powertrain of a windmill accounts for approximately 25 percent of the total equipment cost. In the mining industry, gears and gearboxes can be found in a variety of different applications along the entire process chain such as conveyor drives for extraction, gearboxes for mill drive systems in the processing stage or gearboxes for the stacker reclaimer and special trucks for the transportation process. Most of the gears in these applications also have to transmit high torque, are often subjected to demanding operating conditions and have to achieve long service life. Consequently, large-sized gears can be found in many of these products. 
The general requirements for high performance gear components are a hard case providing adequate fatigue strength, as well as wear resistance and a tough core preventing brittle failure under high impact loads [1]. Accordingly, various alloy concepts, thermo-mechanical and thermo-chemical treatments have been developed to achieve this property combination. Commonly, gears are therefore case carburized. The heat treatment process of case carburizing is complex, requiring a high level of technical knowledge, as well as a profound understanding of the material characteristics. Alloy concepts for medium- and large-sized gear applications significantly vary in different markets due to historical drivers (e.g., automotive, machine building, military), practical experiences, as well as the local preference for certain alloying elements (Table 1).

Table 1. Major carburizing steel grades for medium- and large-sized gears in various geographical markets.

\begin{tabular}{|c|c|c|c|c|c|c|c|c|c|c|c|}
\hline \multirow{2}{*}{ Steel Grade } & \multirow{2}{*}{ Standard } & \multicolumn{10}{|c|}{ Alloy Addition in wt \% } \\
\hline & & & C & $\mathrm{Si}$ & Mn & $\mathbf{P}$ & $\mathrm{S}$ & $\mathrm{Cr}$ & Mo & $\mathrm{Ni}$ & Region \\
\hline \multirow{2}{*}{$20 \mathrm{MnCr} 5$} & \multirow{2}{*}{ EN 10084 (1.7147) } & $\min$. & 0.17 & - & 1.10 & - & - & 1.00 & - & & \multirow{4}{*}{$\begin{array}{l}\text { Western } \\
\text { Europe }\end{array}$} \\
\hline & & $\max$. & 0.22 & 0.40 & 1.40 & 0.035 & 0.035 & 1.30 & - & 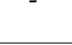 & \\
\hline \multirow{2}{*}{ 18CrNiMo7-6 } & \multirow[b]{2}{*}{ EN 10084 (1.6587) } & $\min$. & 0.15 & - & 0.50 & - & - & 1.50 & 0.25 & 1.40 & \\
\hline & & $\max$. & 0.21 & 0.40 & 0.90 & 0.025 & 0.035 & 1.80 & 0.35 & 1.70 & \\
\hline \multirow{2}{*}{ 15CrNi6 } & \multirow{2}{*}{ EN 10084 (1.5919) } & $\min$. & 0.14 & - & 0.40 & - & - & 1.40 & - & 1.40 & \multirow{2}{*}{$\begin{array}{c}\text { France, } \\
\text { Germany }\end{array}$} \\
\hline & & $\max$. & 0.19 & 0.40 & 0.60 & 0.035 & 0.035 & 1.70 & & 1.70 & \\
\hline \multirow{2}{*}{ 17NiCrMo6-5 } & \multirow{2}{*}{ EN 10084 (1.6566) } & min. & 0.14 & - & 0.60 & - & - & 0.80 & 0.15 & 1.20 & \multirow{2}{*}{ Italy, France } \\
\hline & & $\max$. & 0.20 & 0.40 & 0.90 & 0.025 & 0.035 & 1.10 & 0.25 & 1.50 & \\
\hline \multirow{2}{*}{ SAE 8620} & \multirow{2}{*}{ SAE J1249 } & $\min$. & 0.18 & 0.15 & 0.70 & - & - & 0.40 & 0.15 & 0.40 & \multirow{4}{*}{$\begin{array}{l}\text { North } \\
\text { America }\end{array}$} \\
\hline & & max. & 0.23 & 0.35 & 0.90 & 0.030 & 0.040 & 0.60 & 0.25 & 0.70 & \\
\hline \multirow{2}{*}{ SAE 9310} & \multirow{2}{*}{ SAE J1249 } & min. & 0.08 & 0.15 & 0.45 & - & - & 1.00 & 0.08 & 3.00 & \\
\hline & & max. & 0.13 & 0.35 & 0.65 & 0.025 & 0.040 & 1.40 & 0.15 & 3.50 & \\
\hline \multirow{2}{*}{$20 \mathrm{CrMnTi}$} & \multirow{2}{*}{ GB T 3077-1999 } & $\min$. & 0.17 & 0.17 & 0.80 & - & - & 1.00 & 0.00 & - & \multirow{4}{*}{ China } \\
\hline & & $\max$. & 0.23 & 0.37 & 1.10 & 0.035 & 0.035 & 1.30 & 0.15 & 0.30 & \\
\hline \multirow{2}{*}{ 20CrMnMo } & \multirow{2}{*}{ GB T 3077-1999 } & min. & 0.17 & 0.17 & 0.90 & - & - & 1.10 & 0.20 & - & \\
\hline & & max. & 0.23 & 0.37 & 1.20 & 0.025 & 0.035 & 1.40 & 0.30 & 0.30 & \\
\hline \multirow{2}{*}{ SCM420 } & \multirow{2}{*}{ JIS } & min. & 0.18 & 0.15 & 0.60 & - & - & 0.90 & 0.15 & \multirow{2}{*}{ - } & \multirow{2}{*}{ Japan } \\
\hline & & max. & 0.23 & 0.35 & 0.85 & 0.030 & 0.030 & 1.20 & 0.30 & & \\
\hline
\end{tabular}

Carburizing steels must comply with the following key requirements with regard to component properties and durability:

- Chemical composition/hardenability;

- Homogeneity/microscopic and macroscopic cleanness;

- Mechanical properties (tensile strength, fatigue strength and toughness);

- Wear resistance, contact fatigue strength, bending strength and vibration resistance;

- High and uniform dimensional stability [2].

DIN EN 10084 and ISO 683-11 [3,4] specify the technical delivery conditions for carburizing steel grades. Besides the classification and designation of the steel grades, also the production processes, requirements (e.g., hardenability ranges), as well as the testing and inspection procedures are specified. In addition to these general standards, many end users have issued proprietary delivery specifications, which describe particular demands (e.g., austenite grain size) in more detail. This is a result of the many possible processing routes for the production of carburized components. Depending on the component requirements, different sequences of annealing, hardening and machining are pursued (Figure 1). For instance, when a high dimensional stability of the component is needed, pre-hardening is performed before and stress relieving after machining. It is hence essential to take the entire process chain into consideration when optimizing the material. For the design of large-scale gearboxes, steel grades are commonly selected according to the requirements specified in DIN 3990/ISO 6336, Part 5 [5,6]. Figure 2 
indicates as an example the anticipated tooth root endurance strength of various steel alloys and heat treatment concepts. Within the strength fields, in general, three quality levels-ML, MQ, ME acc. to [5,6] — can be distinguished: grade ML stands for the minimum requirement; grade MQ represents requirements that can be met by experienced manufacturers at moderate cost; grade ME represents requirements that must be aimed at when higher allowable stresses are desirable (Figure 2). It is obvious that the highest strength values are achievable for case carburized gears of quality grade ME. The diagram relates an easily measurable property like, in this case, surface hardness to a complex system property such as the tooth root endurance strength. The fact that for a given surface hardness, a rather wide range of tooth root endurance strength levels can be obtained suggests that alloy composition, microstructure and thermo-chemical treatment have an extremely high impact on the actual gear performance. Another system property of high importance for gear durability is the resistance to gear flank failures like pitting, micropitting, as well as tooth flank fracture. High contact pressure, the status of lubrication, material properties, microstructure and chemical composition influence these system properties. Furthermore, with respect to the flank load carrying capacity, case carburized materials of the highest quality level ME typically show the highest achievable strength values.

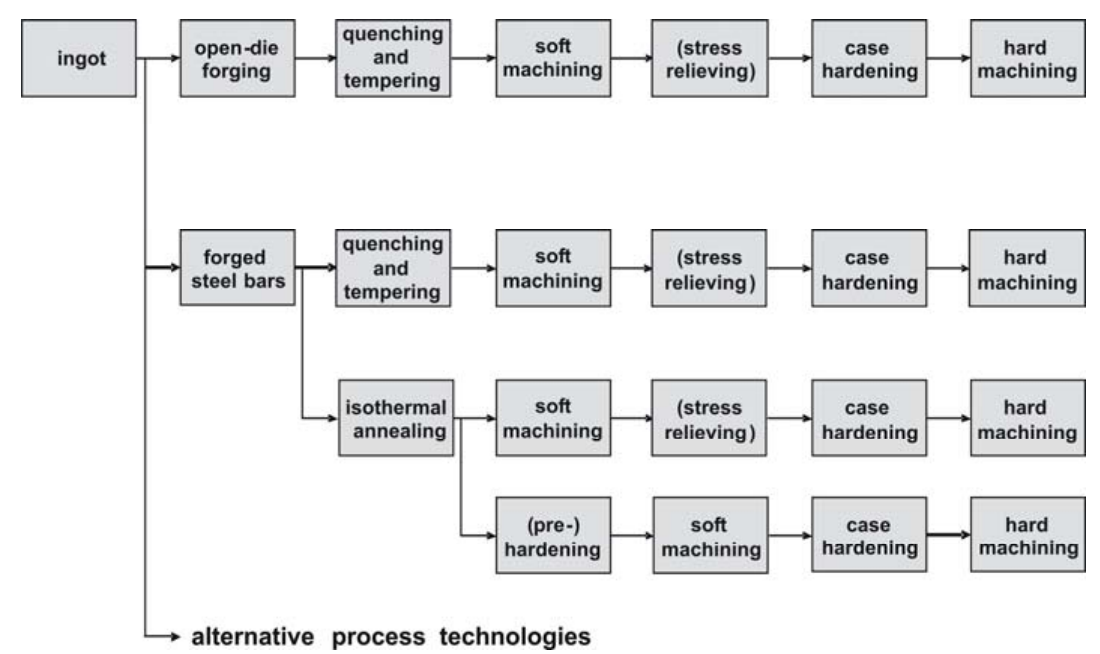

Figure 1. Typical processing routes for the manufacturing of case-hardened components.

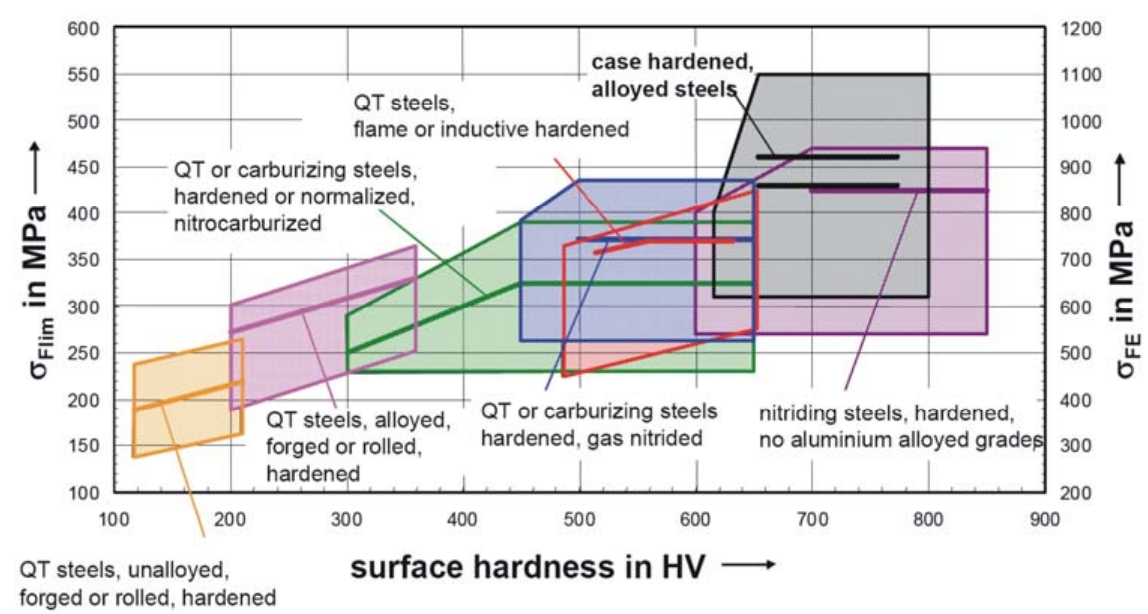

Figure 2. Tooth root load carrying capacity; allowable bending stress numbers according to ISO 6336-5 and the indication of quality levels (ML, MQ, ME) [6].

For both vehicle and industrial transmissions, further optimization of gear steel towards better performance under demanding conditions is necessary. This is amongst others motivated by reducing 
fuel consumption and emissions, as well as a higher load bearing capacity at the surface, in the near surface case, as well as at greater depths below the surface. A secondary target is to design efficient alloying concepts taking the entire processing route into consideration including modified or innovative heat treatments. A fundamental way of dealing with these demands is to adjust the chemical composition of carburizing steels. In this respect, one can principally define two approaches. An economically-driven approach aims at achieving a defined performance spectrum with a cost-reduced alloy concept, whereas a performance-driven approach targets superior properties at equal or moderately increased cost. The current work considers both approaches focusing on modified molybdenum-based alloy concepts including niobium microalloying. Thereby, innovative heat treatment conditions have also been considered. The success of either strategy is verified by using standardized tooth root fatigue tests and back-to-back running tests allowing direct benchmarking against a database of many established gear steel grades.

\section{Optimization Strategy for Carburizing Steels}

\subsection{Gear Fatigue Failure Modes and Failure Mechanism}

The gear load carrying capacity is generally limited by different failure modes. Each failure mode is decisively influenced by the gear design, the gear material characteristics, the operating conditions and the gear lubricant performance. Nevertheless, each single failure mode is dominated by different physical parameters and subject to different failure mechanisms. A profound understanding of the underlying mechanism and of the relevant load and stress conditions, under a particular contemplation of the gear size, are essential requirements in order to select an appropriate gear material with optimized material properties in the entire gear volume to provide a sufficiently high load carrying capacity. Gear failures basically can be divided into material fatigue-related failures and non-fatigue failure modes, which are primarily due to tribological problems in the lubricated contact, such as for instance scuffing. A further differentiation of gear failures is possible based on the failure initiation site. Regarding the location on the gear, this can be either the gear flank or the tooth root area. On the other hand, it is the crack initiation site located at the surface or at greater material depth. All these aspects can result in different requirements towards the material properties in different areas.

Figure 3 shows the main gear failure modes related to material fatigue, which are targeted for optimization in the present investigation. Pitting and tooth root breakage are the typical appearances of fatigue failure in gears. Both failure types are usually initiated at the surface or close to the surface and are characterized by a crack propagating further into the material. While the pitting load capacity is strongly influenced by the Hertzian contact stresses in the gear contact, the tooth root strength is related to bending stresses in the root fillet. Differences in the nature of the contact and bending stresses may result in different requirements regarding the material properties in relevant material areas.
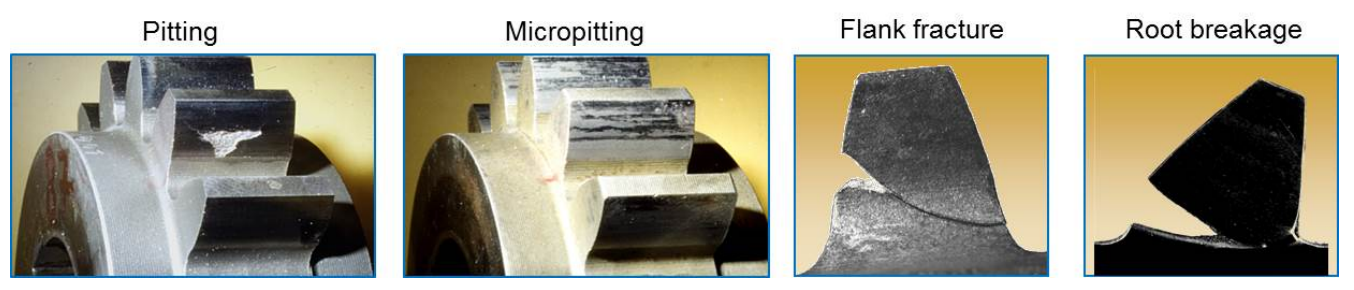

Figure 3. Main gear fatigue failure modes.

Additionally, the failure mode of micropitting can negatively influence the gear performance. Micropitting is most often observed at the surface of the loaded gear flank, typically occurring under unfavorable lubricating conditions. Micropitting can also be considered as a fatigue failure, yet with a crack propagation limited to the near-surface zone. Consequently, micropitting is controlled by the material characteristics in the near-surface zone. Furthermore, the contact load at the flank surface also 
induces stresses deeper in the material. If these stresses exceed the prevailing local strength of the material, subsequent failure with crack initiation below the surface may arise. In the literature, such failure types are referred to as tooth interior fatigue fracture (TIFF), tooth flank fracture or sub-surface fatigue. As the load-induced stresses at greater material depths increase with increasing gear size, the strength properties of the material at a greater material depth consequently gain in importance for large gears.

The stress condition in a gear tooth basically is in relation to the tooth normal force acting in the gear contact, which again depends on the applied torque. This tooth normal force causes contact stresses at the gear flank and bending stresses especially in the root fillet as is schematically indicated in Figure 4. Further influences on the actual stress distribution arise from the gear geometry, the operating conditions and the manufacturing process (residual stress).

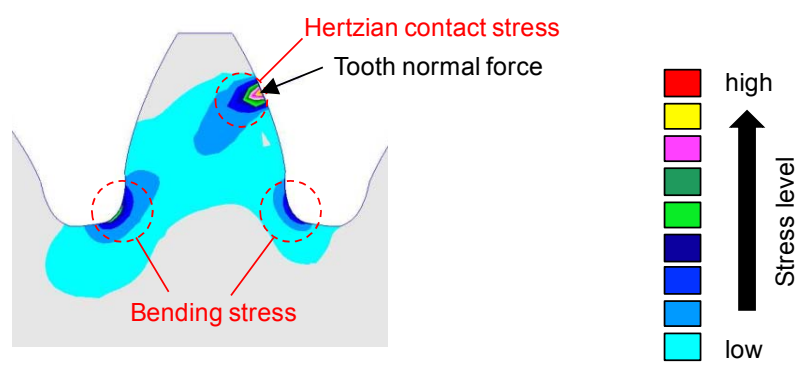

Figure 4. Schematic distribution of stress inside a gear tooth indicating highly loaded areas (Hertzian contact stress at tooth flank, bending stress at tooth root).

Basically, increasing the gear size allows transmitting a higher torque. However, load-induced stresses at greater material depth also become larger with increasing gear size, even if the maximum relevant stress value is comparable. Figure 5 demonstrates exemplarily the distribution of the relevant stresses over material depth for different gear sizes. It is obvious that with increasing gear size, expressed by the radius of curvature $\rho_{C}$ for the gear flank or the gear module $m_{\mathrm{n}}$ for the tooth root, respectively, an adjustment of the hardness profile becomes necessary. This is to keep the allowable stress on a larger level than the actual load-induced stress at any position into the depth. Consequently, with increasing gear size, an increased case hardening depth (CHD) is required. The influence of case hardening depth on the pitting and bending strength of gears is shown in Figure 6.
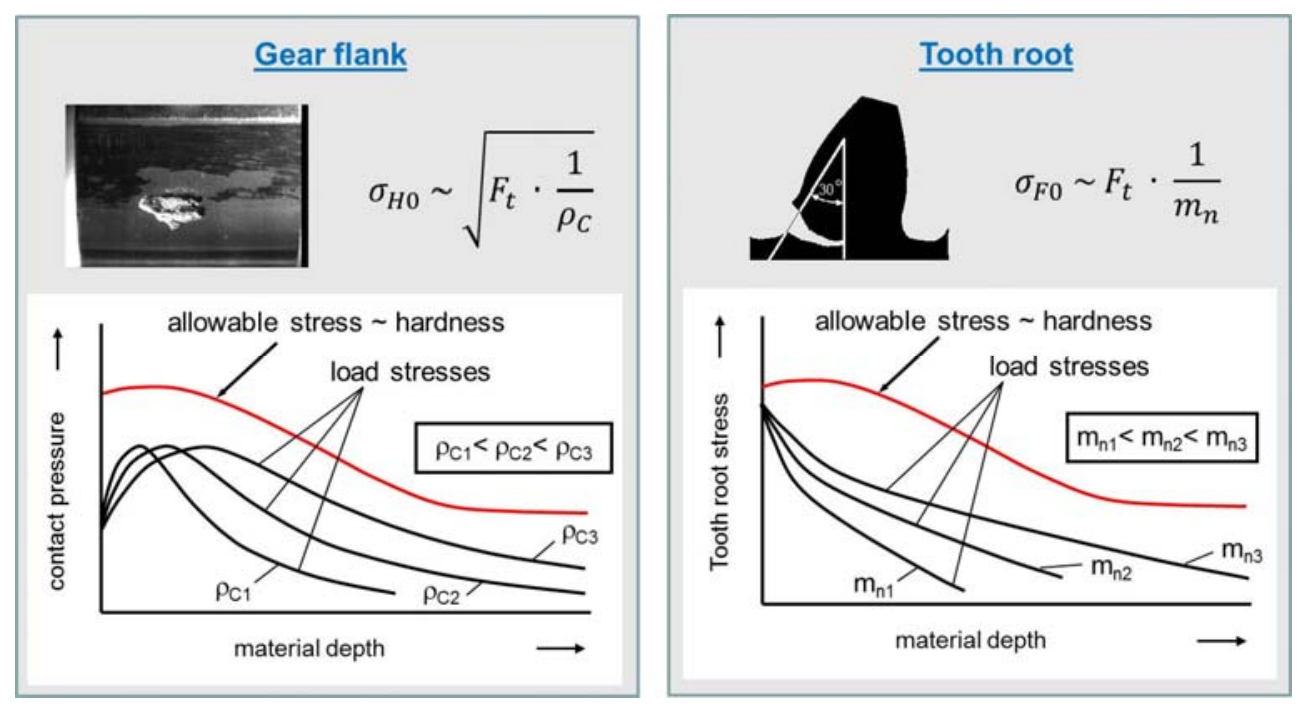

Figure 5. Comparison of gear flank contact pressure (left) and tooth root stress (right) vs. the allowable stress over material depth depending on the gear size represented by the curvature $\rho_{C}$ and module $m_{\mathrm{n}}$ for a given tangential driving force $F_{\mathrm{t}}[7]$. 

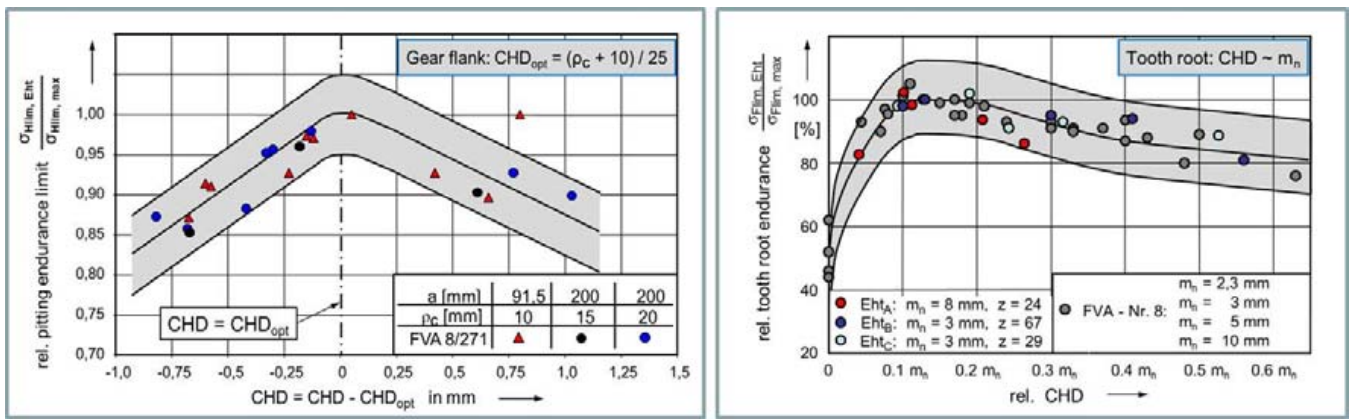

Figure 6. Influence of case hardening depth (Eht is identical to $\mathrm{CHD}$ ) on the relative pitting endurance limit $\sigma_{\text {Hlim }}\left(\right.$ left) and the relative tooth root endurance $\sigma_{\text {Flim }}$ (right) for different gear sizes [8].

Because a different hardness profile also influences the residual stresses (compressive residual stresses are assumed over the complete case carburized layer), not only the material strength, but also the equivalent stress curve are influenced by a different case hardening depth (Figure 7, left). Obviously, the ratio between local equivalent stress and local material strength is more critical for smaller CHD and, in this case, is most unfavorable at a depth that is close to the case-core interface. Consequently, CHD is not only an important influencing parameter for the pitting and bending strength of gears, but may also strongly contribute to minimizing the risk of a crack initiation below the surface and thereby reducing the risk of failure due to tooth flank fracture (Figure 7, right). Furthermore, it is obvious that also increasing the core strength of the gear material may contribute to reducing the risk of a failure initiation at greater material depth.
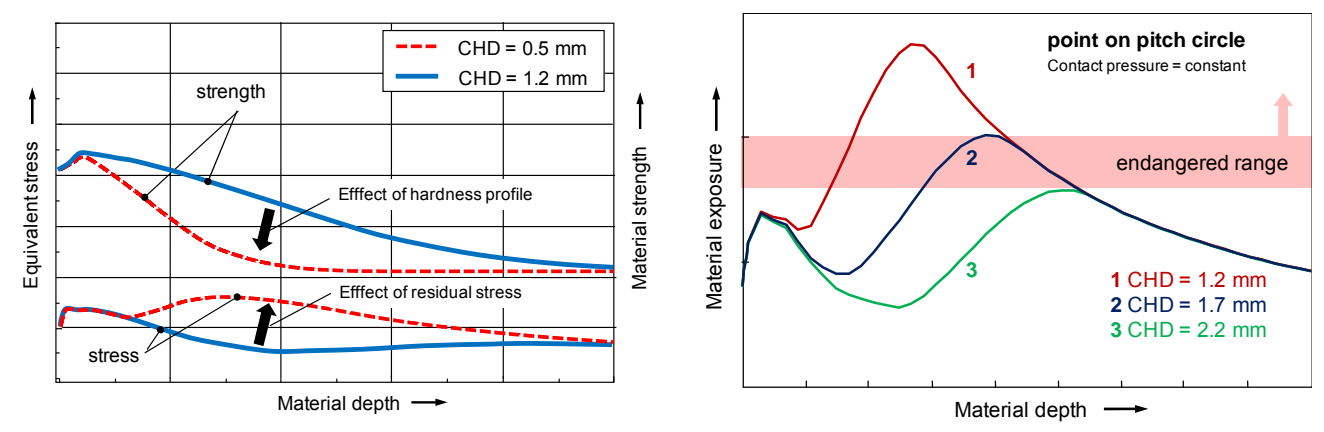

Figure 7. Exemplary influence of varying case hardening depth on the material strength (left), equivalent stress (left) and material exposure as a function of depth indicating the risk of sub-surface overloading (right) [7].

\subsection{Requirements on Material Properties for Large Gear Sizes}

An increased case hardening depth required for large gear sizes is correlated with an increased carburizing time. Longer carburizing times will affect further material properties and result in special demands on the material characteristics for large-sized gears. Some major requirements for optimized materials with special regard to large gear applications are summarized in the following:

- Case hardening depth: adequate CHD is necessary to achieve the required fatigue strength at the case and core: for the effects, see Figures 6 and 7; the gear material has to be suitable for long heat treatment process times to achieve the high CHD required for large gears;

- Surface hardness: a minimum surface hardness of $660 \mathrm{HV}$ or $58 \mathrm{HRC}$ (Rockwell-C hardness) is required according to existing standards in order to achieve allowable stress numbers for pitting and bending of quality levels MQ and ME; higher surface hardness values do not increase fatigue resistance, but make machinability more difficult; in contrast, wear resistance of the surface typically increases with increased surface hardness; 
- Core tensile strength and toughness: increased core hardness is known to especially influence the tooth root bending strength; higher core toughness allows higher core hardness for optimized strength; furthermore, increased core strength and toughness are assumed to reduce the risk of tooth flank fracture damages; gear steels with improved hardenability are required to achieve the desired properties for large gears;

- Microstructure and grain size: fine acicular martensite in the case, as well as fine acicular martensite and bainite in the core are required for optimized load carrying capacity; fine grain size, particularly ASTM 8 and finer, is known to positively impact gear flank and tooth root load carrying capacity; adequate alloying elements are required to ensure grain size stability and fine microstructure even at long process times of carburization;

- Residual austenite: a certain amount of retained austenite in the case is, due to its ductility, assumed to be beneficial for micropitting load capacity and may also contribute to an improved pitting strength; a higher amount of residual austenite may reduce case hardness and bending strength; up to $25 \%$ finely-dispersed retained austenite is allowable according to existing gear standards;

- Cleanness: non-metallic inclusions are known to act as local stress raisers; depending on inclusion size and its chemical composition, the gear load carrying capacity, especially the risk of a crack initiation below the surface, may be diminished; as the highly stressed material volume increases with the gear size, the probability of critical inclusions located in critical material sections is increased; consequently, high demands on the cleanness of the gear material especially for large gears result;

- Area reduction ratio, material homogeneity and intergranular oxidation depth: these are further parameters that gain special importance for large gears; requirements according to existing gear standards have to be fulfilled even for larger gear sizes; intergranular oxidation can act as a fatigue fracture initiation site and may reduce the fatigue strength of the tooth;

- Hardenability: improved hardenability of the gear material is a basic requirement to achieve several of the above described properties for large gears.

Figure 8 demonstrates the influence of gear size on the tooth root bending strength. Basically, allowable stress numbers decrease with increasing gear size due to different size effects. Nevertheless, the results clearly prove that for large gear sizes, gear steel grades with better hardenability (17CrNiMo6, 17NiCrMo14) achieve significantly higher bending strength values compared to gear steel grades with lower hardenability $(16 \mathrm{MnCr} 5)$. The difference in gear strength depending on material hardenability increases with the gear size. Consequently, appropriate alloying elements achieving high material hardenability and ensuring adequate material characteristics are essential for high performance carburizing steels in order to meet the requirements of large-sized gears and to provide an adequate gear load carrying capacity.

As the performance reference for the current study, steel grade 18CrNiMo7-6 (1.6587) has been selected since this grade is currently being widely used for demanding gear applications in Europe (refer to Table 1 for alternative gear steel grades used in other geographical regions). The task was to modify the main alloying elements in a way to achieve either the same performance at lower alloy cost or better performance at similar alloy cost. The following approach is considered to be relevant in this respect:

- Improving hardenability;

- Increasing core tensile strength and toughness;

- Increasing fatigue strength in both the case and core;

- Reducing quench distortion and thus negative acting tensile residual stresses;

- Improving microstructural stability to withstand elevated temperatures during manufacturing and service. 

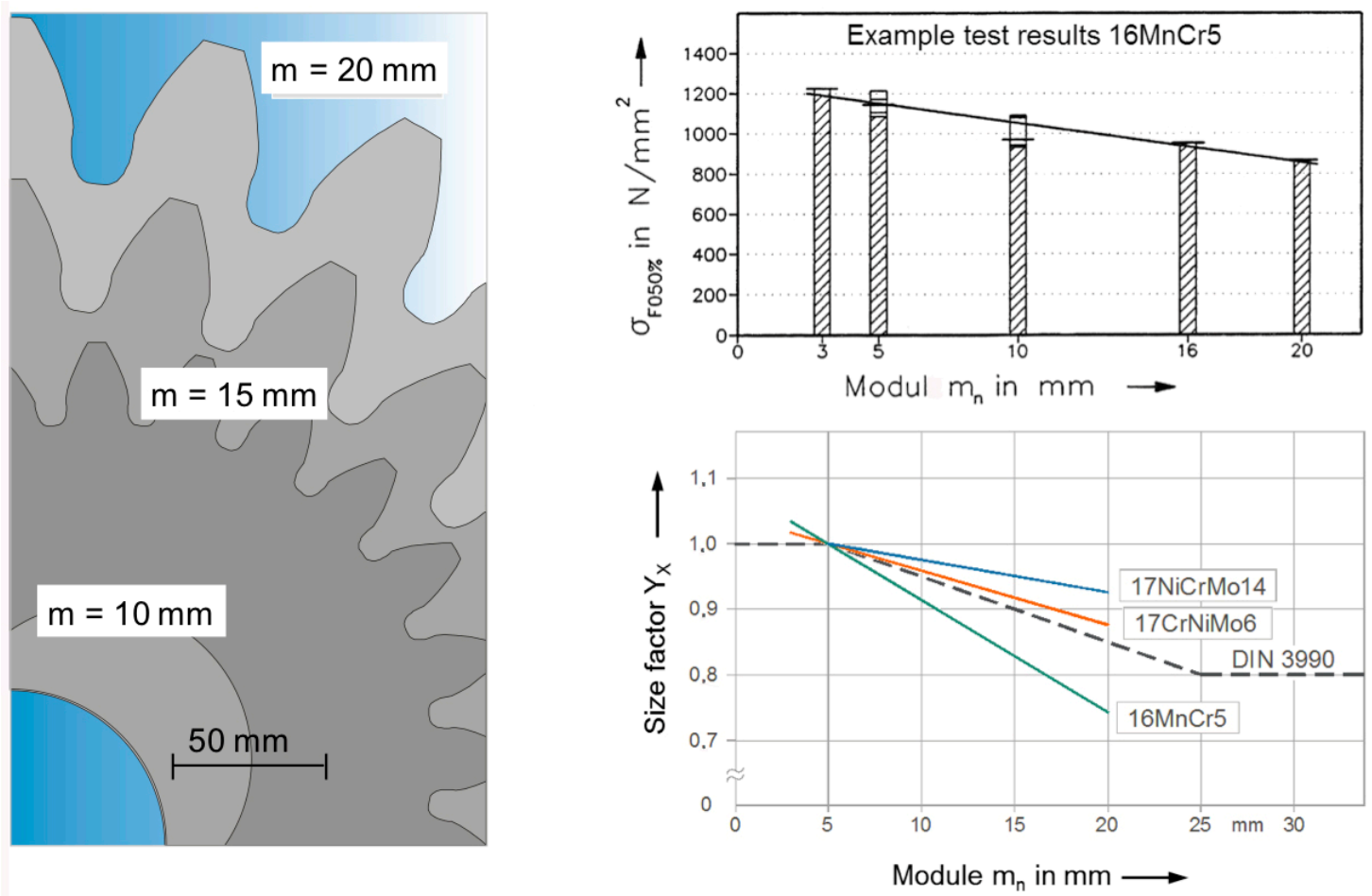

Figure 8. Influence of gear size on tooth root bending strength for gear materials with different hardenability; (left) examples of investigated test gears, (upper right) experimentally-determined tooth root endurance limit for material $16 \mathrm{MnCr} 5$ depending on gear size and (lower right) size factor for tooth root bending strength for different gear steels [9].

A fundamental way to deal with these issues is to adjust the chemical composition of the carburizing steel. Accordingly, the chemical composition of carburizing steels can be further developed to achieve the above goals using the following guidelines:

- $\quad$ Minimize intergranular oxidation $\rightarrow$ reduce $\mathrm{Si}, \mathrm{Mn}$ and $\mathrm{Cr}$ [10];

- $\quad$ Prevent MnS inclusions $\rightarrow$ reduce S, limit Mn;

- $\quad$ Prevent TiN inclusions $\rightarrow$ control Ti/N wt $\%$ ratio close to three;

- Improve hardenability $\rightarrow$ increase Mo;

- Improve toughness $\rightarrow$ increase Ni and Mo;

- $\quad$ Refine and homogenize grain size $\rightarrow$ balance $\mathrm{Nb}, \mathrm{Ti}, \mathrm{Al}$ and $\mathrm{N}$ microalloying addition;

- $\quad$ Strengthen grain boundaries $\rightarrow$ reduce $\mathrm{P}$ and $\mathrm{S}$, add $\mathrm{Mo}$ and $\mathrm{Nb}$.

Some previous developments of improved gear steels put the focus on high nickel additions and reduced molybdenum content (Figure 9). Although this approach provides an elevated core strength and generally high toughness, the hardness in the near-surface zone can be too low, as nickel is a very efficient austenite stabilizer. On the other hand, raising the carbon and molybdenum content, optionally in combination with microalloying elements, shifts the hardenability curve entirely upwards, thus providing a sufficient safety margin against local overloading in the critical area below the surface. This second approach may be leading to lower toughness especially when the nickel content is being reduced. However, refining and homogenizing the martensitic microstructure (packet size) can regain toughness. It was shown on the example of $18 \mathrm{CrNiMo7}-6$ that below an average martensite packet size of $20 \mu \mathrm{m}$, the impact toughness strongly increases [11]. Since the packet size strongly correlates with the prior austenite grain size [11,12], control and refinement of the latter one across the entire processing chain is an appropriate means of improving toughness. 


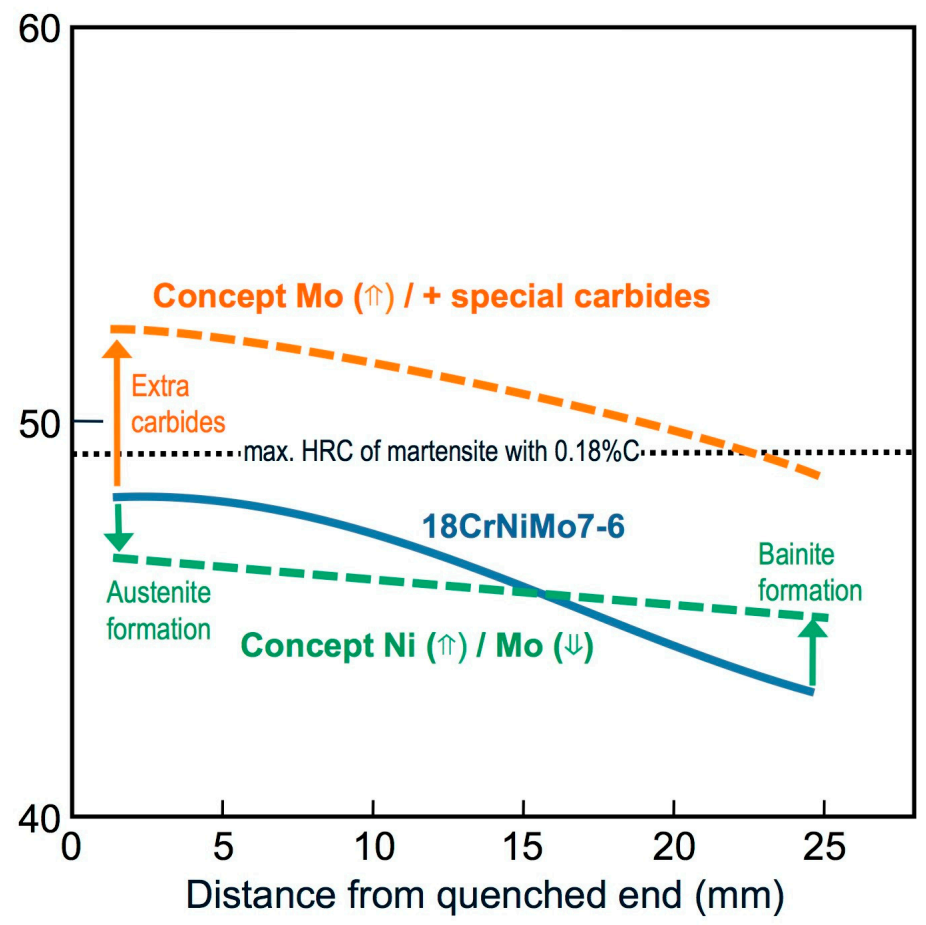

Figure 9. Effect of alloy modifications on hardenability as compared to standard 18CrNiMo7-6 steel.

\section{Controlling Grain Size in Carburizing Steels}

Many studies have been indicating that prior austenite grain size control in carburizing steel can be effectively achieved by using niobium microalloying in combination with other microalloys such as titanium, aluminum and nitrogen [13-20]. The developed concepts have been used to generally refine and homogenize the grain size under standard case carburizing conditions. Furthermore, it has been demonstrated that high temperature carburizing becomes possible without violating grain size restrictions, thus allowing a faster furnace throughput. This is particularly beneficial when a larger case depth is required like in gears for trucks and heavy machinery. Additionally, a production concept for fine-grained carburizing steel has been developed based on an aluminum-free melt. This is to fully eliminate brittle inclusions deteriorating toughness and fatigue resistance in the steel.

The obstruction of grain coarsening is based on a pinning effect of precipitates on the austenite grain boundary. For efficient grain boundary pinning, a suitable size and distribution of precipitates is necessary, which again depends on the prior thermo-chemical treatment, as well as the carburizing temperature. Above a certain limiting carburizing temperature, the precipitates coarsen or dissolve, and their pinning effect is lost. It appears to be most efficient keeping as much as possible microalloy content in solid solution during thermo-chemical processing, which then can precipitate as fine-sized and homogeneously-distributed particles during up-heating to carburizing temperature. Niobium has the beneficial characteristic of low solubility in such steel, similar to titanium, providing temperature-stable precipitates. Yet, niobium has a lower affinity to nitrogen and does not form coarse nitrides, contrary to titanium. Furthermore, its precipitation kinetics is slower so that niobium remains longer in solution, forming finer and more dispersed precipitates. It was also found that mixed precipitates of $\mathrm{Nb}$, Ti and $\mathrm{N}$ are better resistant against dissolution at a very high austenitizing temperature. Therefore, a microalloy combination of low $\mathrm{Ti}$ (sub-stoichiometric to $\mathrm{N}$ ) and $\mathrm{Nb}$ in the range of $0.03-0.10 \%$ has been proven to be most efficient.

Adding niobium in combination with titanium to the reference grade $18 \mathrm{CrNiMo7-6}$ has a marked effect on the grain size distribution as shown in Figure 10a. Not only the grain size is generally much finer, but also the scattering range becomes narrower. The microalloyed variant safely avoids prohibited grain sizes despite high carburizing temperature $\left(1030^{\circ} \mathrm{C}\right)$ and the long holding time 
$(25 \mathrm{~h})$. Similar good results of grain size stability have been obtained with modified variants of $25 \mathrm{MoCr} 4$ and 20CrMo5 grades (Figure 10b). The $\mathrm{Nb}$ and Ti dual microalloyed 25MoCr4 variant reveals resistance to coarsening up to a $1050{ }^{\circ} \mathrm{C}$ carburizing temperature, whereas the $\mathrm{Nb}$-only microalloyed $20 \mathrm{CrMo} 5$ variant is stable up to $1000{ }^{\circ} \mathrm{C}$. The latter alloy indicates that for very high carburizing temperatures, indeed, the addition of multiple microalloys appears to increase the temperature stability of pinning precipitates. However, at standard carburizing conditions below $1000{ }^{\circ} \mathrm{C}$, also the $\mathrm{Nb}$-only microalloyed concept exhibits very fine austenite grain size with a rather narrow size distribution.

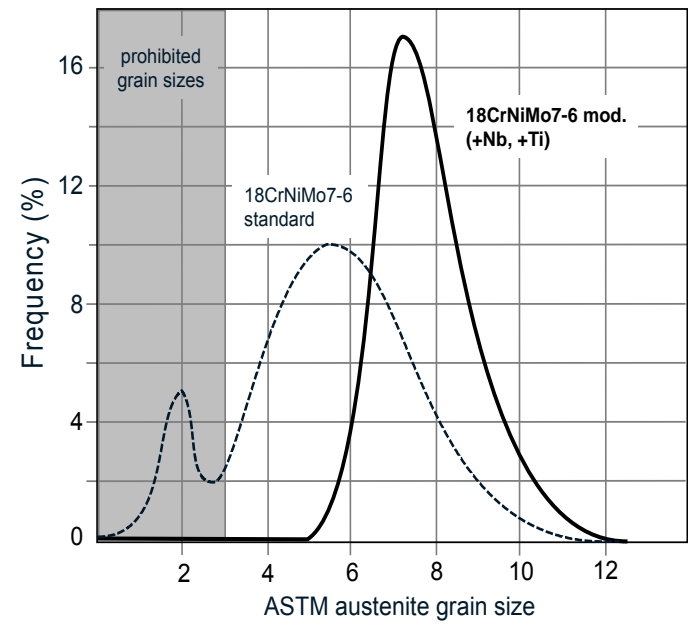

(a)

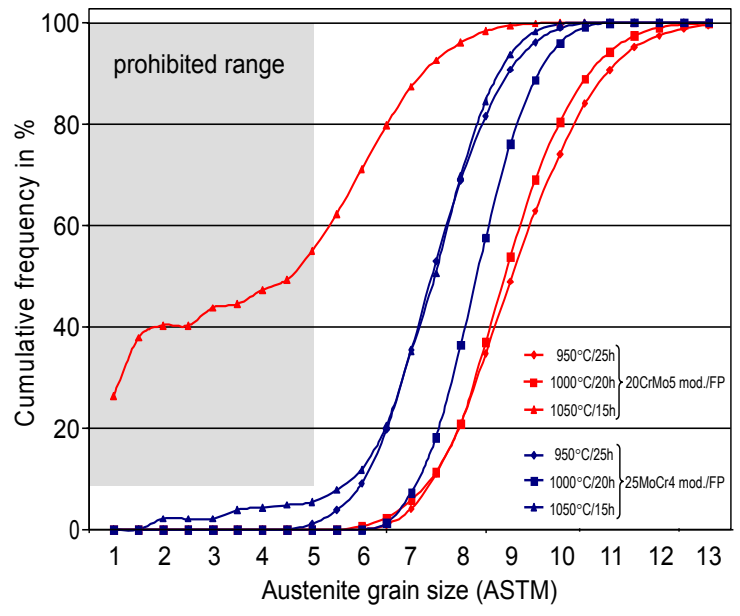

(b)

Figure 10. Controlling grain size in carburizing steel: (a) grain size distribution of a $\mathrm{Nb}+\mathrm{Ti}$ microalloyed 18CrNiMo7-6 (1.6587) heat-treated compared to a conventional analysis (carburizing conditions: $1030{ }^{\circ} \mathrm{C} / 25 \mathrm{~h}$ ); (b) grain size stability under various carburizing conditions for $\mathrm{Nb}$ microalloyed 20CrMo5 (1.7264) and 25CrMo4 (1.7325).

The martensite start temperature depends on the austenite grain size [21]. The smaller the austenite grain size, the lower is the martensite start temperature. Accordingly, in a mixed grain size structure, transformation locally occurs at different temperatures. This situation will lead to the generation of residual stresses due to the volume change when the microstructure transforms from austenite to martensite. The earlier formed martensite islands cannot plastically accommodate the transformational volume change of the later formed martensite islands. Hence, imbalanced elastic stresses cause a macroscopic distortion of the quenched component. It has been experimentally confirmed that a larger grain size scatter results in a larger scatter of distortion (Figure 11a) [22]. The distortion has to be corrected by straightening or hard machining. This is not only costly, but also reduces the thickness of the case layer when performing hard machining. Furthermore, residual stresses overlay the applied load stresses. Especially tensile residual stresses can cause premature failure, for instance under fatigue conditions.

Consequently, microalloying of case carburizing steel leading to reduced grain size scatter as demonstrated above is expected to lower quench distortions. This could indeed be verified for components manufactured from the modified variant of $25 \mathrm{MoCr} 4(320 \mathrm{ppm} \mathrm{Nb}, \mathrm{pm} \mathrm{Ti}, 160 \mathrm{ppm} \mathrm{N})$ shown in Figure 11b. The material was continuously cast into bar. The bar was FP (ferrite-pearlite) annealed before cold extrusion and then again FP annealed. Carburization occurred at $980{ }^{\circ} \mathrm{C}$ for $195 \mathrm{~min}$ to a target case depth of $0.95 \mathrm{~mm}$ with a total furnace residence of $400 \mathrm{~min}$. The components were then quenched in an oil bath (Isorapid 277) held at $60{ }^{\circ} \mathrm{C}$. Subsequently part distortion was characterized by roundness deviation measurements at five positions as shown in Figure 11b. It is obvious that the microalloyed variant has a much lower roundness deviation as compared to the standard alloy. At each measuring position, the deviation was reduced by approximately $50 \%$ resulting in a similar reduction of straightening efforts. The cost savings achieved by such reduced straightening 
or hard machining efforts likely compensate the cost for the microalloys. If the available equipment allows high temperature carburizing, severe process time savings can be realized. For instance, for producing a target case depth of $1.5 \mathrm{~mm}$, the total treatment cycle time can be reduced by 25 and 40 percent when the carburizing temperature is raised to $980{ }^{\circ} \mathrm{C}$ and $1030^{\circ} \mathrm{C}$, respectively, as compared to a standard carburizing temperature of $930{ }^{\circ} \mathrm{C}$.

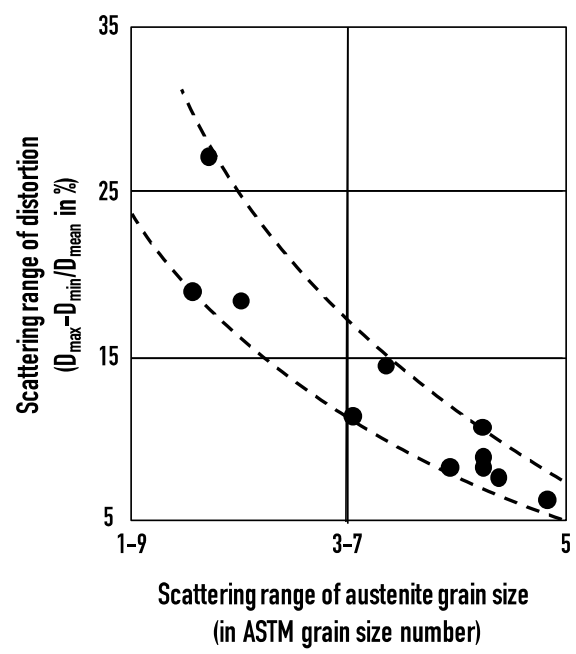

(a)

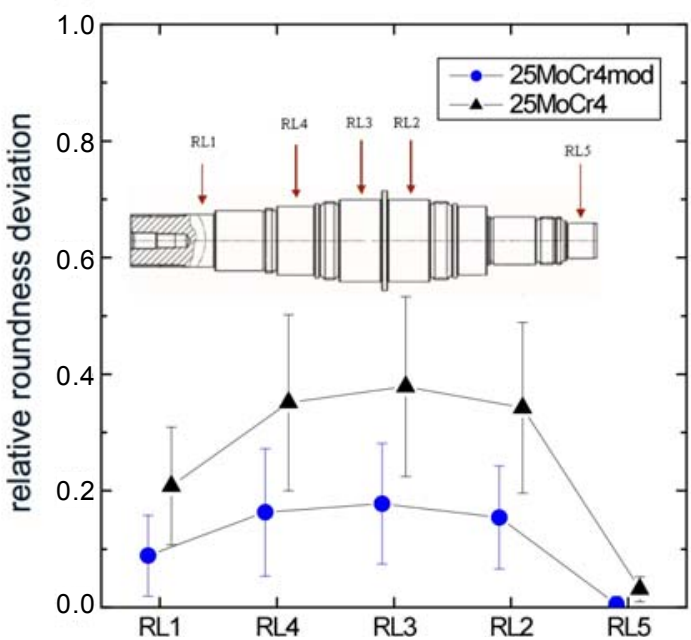

(b)

Figure 11. Reducing quench distortion in carburizing steel: (a) influence of mean prior austenite grain size scattering in steel $16 \mathrm{MnCr} 5$ (1.7131) on quench distortion [22]; (b) roundness deviation of a heat-treated transmission shaft measured at five positions for standard 25MoCr4 (1.7325) and 25MoCr4 modified by $\mathrm{Nb}$-microalloying.

\section{Increasing Hardenability and Tempering Resistance}

As outlined above, it is of high interest to avoid a steep hardness gradient in the transition zone from the case layer to the core material. Therefore, the hardenability of the alloy must be improved. Several alloying elements, besides carbon, contribute to hardenability, such as: molybdenum, manganese, chromium, nickel, as well as boron microalloying. For cost reduction reasons for the alloys, the use of higher manganese and chromium additions, eventually combined with boron microalloying, has been favored for many gear applications. However, such a cost-reduced alloy concepts, although providing good hardenability, have limitations in terms of toughness and tempering resistance. Besides, the limitation of intergranular oxidation requires reduced $\mathrm{Mn}, \mathrm{Cr}$ and also Si levels. In the other extreme, alloy producers have developed richly-alloyed steels for those applications where transmission failure causes high replacement and outage costs.

An example is $15 \mathrm{NiMoCr} 10-4$ (C: $0.15 \%$, Si: $1.1 \%, \mathrm{Cr}: 1 \%$, Mo: $2 \%$ and Ni: $2.5 \%$ ), which is used in high-end applications, e.g., in aerospace or Formula-1 gears. However, such steel requires special melting technology and is, thus, not widely available. Comparing this steel to another high-Ni steel (14NiCrMo13-4), the increase of the molybdenum content from $0.25 \%-2.0 \%$ brings about a significant improvement of hardenability, surface hardness and also tempering resistance [23] (Figure 12a). The high tempering resistance of the material bears two important advantages. Firstly, it allows performing duplex treatments, i.e., the case-hardened surface is exposed to a second treatment, such as PVD coating or plasma nitriding (PN), for further increasing surface hardness. These treatments are usually performed in a temperature window of $300{ }^{\circ} \mathrm{C}$ to $500{ }^{\circ} \mathrm{C}$. It is thus a prerequisite that the hardness obtained in the underlying material after quenching from the carburizing temperature not be degraded by the second heat cycle. Secondly, many conventional case carburizing steel grades are restricted to a maximum operating temperature of $120^{\circ} \mathrm{C}$ to $160^{\circ} \mathrm{C}$. A steel grade with high tempering 
resistance can be operated at higher temperatures without degrading. Elevated operating temperatures may occur for instance by frictional heating when the transmission experiences lubrication problems.

Good tempering resistance in a typical gear steel base alloy can also be achieved with lower molybdenum additions, as indicated in Figure 12b. Already, a Mo addition of $0.5 \%$ to $0.7 \%$ provides good resistance against softening for tempering parameters up to around 16. Resistance against softening under a tempering parameter of 16 means that a secondary treatment at a temperature of $450{ }^{\circ} \mathrm{C}$ for up to $10 \mathrm{~h}$ should be sustainable. This condition is typical for plasma nitriding.

Microalloying of $\mathrm{Nb}$ further enhances the tempering resistance, obviously as the result of a synergy effect with Mo. Molybdenum and niobium have to some extent similar metallurgical effects. Both exert strong solute drag on grain boundaries, as well as dislocations [24] and also lower the activity of carbon [25]. These fundamental effects are noticed by delayed recovery or recrystallization, as well as a reduced rate of pearlite growth, thus increased hardenability. The solubility of both elements in austenite is however very different. Molybdenum has a good solubility [26], whereas that of niobium is low [27]. Therefore, niobium precipitates as $\mathrm{NbC}$ particles at rather high temperatures. Manganese, chromium and particularly molybdenum increase the solubility of niobium in austenite [28]. Accordingly, more niobium will remain in solution after quenching from austenitizing temperature, which is then available for fine precipitation during tempering treatment acting against softening.

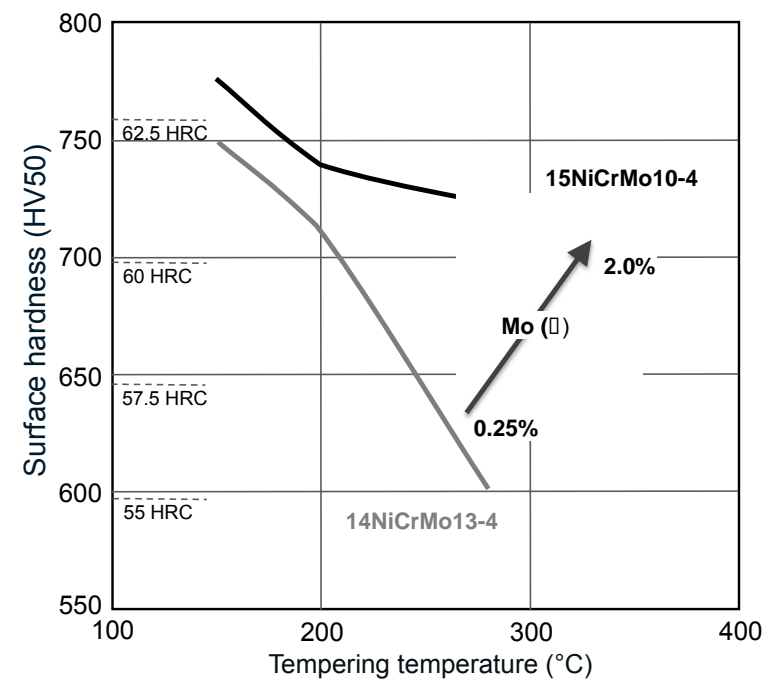

(a)

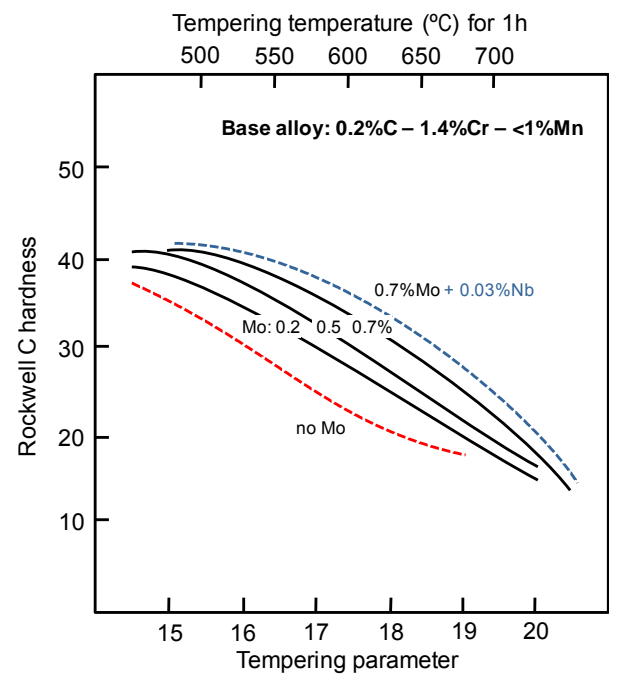

(b)

Figure 12. Increasing tempering resistance in carburizing steel: (a) surface hardness of the carburized layer in relation to tempering temperature and the effect of increased molybdenum content; (b) effect of tempering resistance as a function of the molybdenum content and synergy effect with niobium (tempering parameter $=T \times(20+\log t) \times 10^{-3}(T$ in $\mathrm{K}, t$ in $\mathrm{h})$ ).

\section{Modification and Testing of Carburizing Steels}

Based on the individual and synergetic effects of alloying elements described before, the intended processing route and the desired property profile, two modified alloy concepts have been designed (Table 2) for a full-scale production trial including gear running tests. One of the developed alloy designs (Concept V1) can be considered as a modified $20 \mathrm{MnCr} 5$ grade. It is targeting higher performance than that of $18 \mathrm{CrNiMo7}-6$ at similar alloy cost. The content of carbon is increased for higher maximum hardness while Mo and $\mathrm{Ni}$ are added for increased hardenability and tempering resistance. The other developed alloy design (Concept V2) can be considered as modified 20CrMo5 grade added with nickel, which has a lower total alloy cost than $18 \mathrm{CrNiMo7-6}$, yet aiming at similar performance. In both concepts, niobium microalloying is applied for austenite grain size control. 
The achieved mechanical properties of both developed case carburizing steels obtained after heat treatment indeed correspond to the postulated expectations (Figure 10 and Table 3). The hardenability behavior of Concept V1 is superior to that of 18CrNiMo17-6, whereas that of Concept V2 is within the hardenability range of the reference grade. After an austenitizing treatment at $880{ }^{\circ} \mathrm{C}$ for a duration of $2 \mathrm{~h}$ followed by quenching in oil and holding at $180{ }^{\circ} \mathrm{C}$ for $2 \mathrm{~h}$, Concept V1 shows clearly better tensile and fatigue strength, while Concept V2 nearly exactly matches the strength of the reference grade. The toughness of both developed steels is lower than that of $18 \mathrm{CrNiMo7}-6$ due to the reduced nickel alloy content, yet remains still at a good level.

Table 2. Chemical composition of developed case carburizing steels (alloy additions in wt \%).

\begin{tabular}{cccccccc}
\hline Steel Grade & $\mathbf{C}$ & $\mathbf{S i}$ & $\mathbf{M n}$ & $\mathbf{C r}$ & $\mathbf{M o}$ & $\mathbf{N i}$ & $\mathbf{N b}$ \\
\hline Concept V1 & 0.26 & 0.12 & 1.46 & 1.23 & 0.54 & 0.91 & 0.03 \\
Concept V2 & 0.21 & 0.25 & 1.17 & 1.15 & 0.21 & 0.22 & 0.04 \\
\hline
\end{tabular}

Table 3. Mechanical properties of developed case carburizing steels (hardened at $880{ }^{\circ} \mathrm{C} / 2 \mathrm{~h}+$ oil $\left./ 180^{\circ} \mathrm{C} / 2 \mathrm{~h}\right)$.

\begin{tabular}{cccc}
\hline Property & Concept V1 & Concept V2 & 18CrNiMo7-6 \\
\hline Tensile strength, $R_{\mathrm{m}}(\mathrm{MPa})$ & 1758 & 1182 & 1182 \\
Impact energy, $\mathrm{A}_{\mathrm{v}}(\mathrm{J})$ & 47 & 55 & 80 \\
Rotating fatigue limit $\sigma_{\left(50 \% @=10^{7}\right)}(\mathrm{MPa})$ & 722 & 491 & 510 \\
Hardness at $11 \mathrm{~mm}$ depth $(\mathrm{HRC})$ & 51 & 44 & 41 \\
Hardness at $25 \mathrm{~mm}$ depth $(\mathrm{HRC})$ & 50 & 36 & 36 \\
\hline
\end{tabular}

The heat treatment behavior of the developed alloys has been tested by a carburizing process operated at $1030{ }^{\circ} \mathrm{C}$ to a nominal case depth range of $0.95 \mathrm{~mm}$ to $1.2 \mathrm{~mm}$. This originated from the gear running tests to be executed with a module of 5-mm gears actually requiring a $0.75 \mathrm{~mm}$ to $1.0 \mathrm{~mm}$ case depth. The additional case depth was intended to compensate for grinding losses during hard machining of the carburized gear. For determining the depth of the case layer, a limit hardness of 550 HV was defined according to ISO 6336-5. The targeted surface hardness was set to $680 \mathrm{HV}-700 \mathrm{HV}$. Additionally, a secondary plasma nitriding treatment has been also performed at $400{ }^{\circ} \mathrm{C}$ and $440{ }^{\circ} \mathrm{C}$, respectively. Table 4 summarizes the hardness data for the various pilot heat treatments. In the as-quenched condition after carburizing, both grades fulfill the requirements. Both alloy concepts sustain a tempering treatment at $200{ }^{\circ} \mathrm{C}$. Concept V2 however does not retain sufficient hardness after plasma nitriding treatment. On the contrary, Concept V1, due to its increased tempering resistance, shows very high surface hardness of around $1000 \mathrm{HV}$ after plasma nitriding, whereas the core hardness is reduced. Nevertheless, a core hardness of more than $400 \mathrm{HV}$ still represents a high value. It thus appears that Concept V1 by some further optimization has the potential of fulfilling the case depth requirements at secondary treatment temperatures up to $440{ }^{\circ} \mathrm{C}$. A further increase of the molybdenum content towards $0.7 \%$ (Figure 9 ) and fine-tuning of the microalloy addition are thought to be the most promising ways to achieve the necessary tempering resistance.

Table 4. Hardness characteristics of steels after various heat treatments.

\begin{tabular}{|c|c|c|c|c|c|c|}
\hline \multirow{2}{*}{$\begin{array}{c}\text { Treatment after } \\
\text { Carburizing at } 1030{ }^{\circ} \mathrm{C}\end{array}$} & \multicolumn{3}{|c|}{ Concept V1 (20MnCr5 mod.) } & \multicolumn{3}{|c|}{ Concept V2 (20CrMo5 mod.) } \\
\hline & $\begin{array}{l}\text { Surface } \\
\text { (HV1) }\end{array}$ & $\begin{array}{l}\text { Core } \\
\text { (HV10) }\end{array}$ & $\begin{array}{l}\mathrm{CHD}_{550 \mathrm{HV} 1} \\
\text { (mm) }\end{array}$ & $\begin{array}{l}\text { Surface } \\
\text { (HV1) }\end{array}$ & $\begin{array}{c}\text { Core } \\
\text { (HV10) }\end{array}$ & $\begin{array}{c}\mathrm{CHD}_{550 \mathrm{HV} 1} \\
(\mathrm{~mm})\end{array}$ \\
\hline As quenched & 769 & 544 & 2.04 & 786 & 408 & 1.28 \\
\hline$-70^{\circ} \mathrm{C} / 2 \mathrm{~h}+200^{\circ} \mathrm{C} / 2 \mathrm{~h}$ & 717 & 505 & 1.53 & - & - & - \\
\hline $200^{\circ} \mathrm{C} / 2 \mathrm{~h}$ & - & - & - & 672 & 430 & 1.20 \\
\hline Plasma nitriding $400^{\circ} \mathrm{C}$ & 994 & 432 & 0.8 & 707 & 416 & 0.25 \\
\hline Plasma nitriding $440^{\circ} \mathrm{C}$ & 1009 & 422 & 0.35 & 570 & 395 & 0.1 \\
\hline
\end{tabular}


The operational performance of the developed steel grades (V1 and V2) was tested and benchmarked at FZG, Technical University of Munich, Germany. The tooth root load carrying capacity was investigated in a pulsator rig (Figure 13a). Investigations on the flank load carrying capacity were performed by running tests on a back-to-back gear test rig (Figure 13b) according to DIN ISO 14635-1 [29]. The test gears for these investigations were case hardened after the gear milling. Subsequent to case carburizing, the test gears were mechanically cleaned by shot blasting. The flanks, as well as the tooth roots of the test gears for the investigations on the tooth root bending strength were not ground. The gear flanks of the test gears for the gear running tests were finally ground to a gear quality of $Q \leq 5$ and a surface roughness $R a \leq 0.3 \mu \mathrm{m}$. In order to reduce the effects of the premature contact profile, modifications in the form of tip relief were applied to the gears for the running tests.

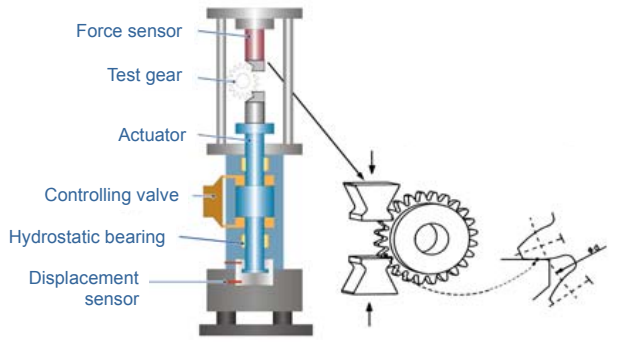

(a)

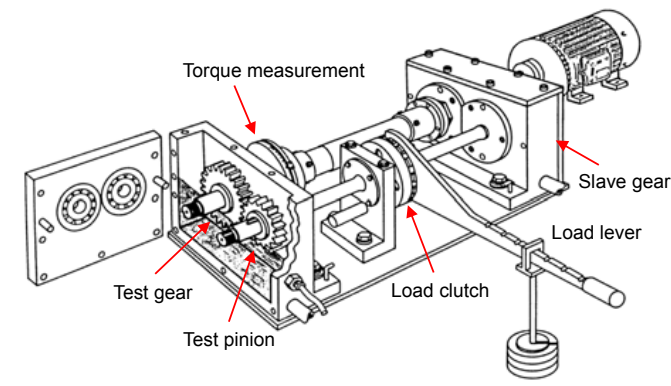

(b)

Figure 13. Equipment for gear testing used at FZG: (a) pulsator test rig for investigations of the tooth root load carrying capacity; (b) back-to-back gear test rig for investigations of the flank load carrying capacity.

For the experimental investigations on the tooth root bending strength standard pulsator test, gears with a gear module $m_{\mathrm{n}}=5$, number of teeth $z=24 \mathrm{~mm}$ and face width $b=30 \mathrm{~mm}$ were used. For'the running tests, spur gears with a module $m_{\mathrm{n}}=5 \mathrm{~mm}$, a gear ratio of $17 / 18$ and a face width $b=14 \mathrm{~mm}$ were used. Both test gear types are typical for the examination of bending strength respectively pitting load capacity of case carburized gears and according to the specifications of ISO 6336 for reference test gears.

The tooth root load carrying capacity is one of the determining factors in gear design. Besides the strength of the material itself, the existing state of stress (load-induced stresses and residual stresses) significantly influences the tooth root load carrying capacity. The mechanical cleaning procedure by shot blasting as used in this test program introduces compressive stresses in the sub-surface zone and is beneficial to fatigue resistance (see also Figure 14a) [30]. The current tooth root bending fatigue tests were carried out under a constant pulsating load with a frequency of $90 \mathrm{~Hz}$ and continued until the limiting number of load cycles of $6 \times 10^{6}$ was reached or tooth root breakage occurred. Gear standards generally consider $3 \times 10^{6}$ as the beginning of the endurance range for bending strength. For each alloy concept, a complete S-N-curve was determined based on a number of approximately 25 test points. The endurance strength level of the S-N-curve was determined using the "stair-step-method" based on at least 10 data points for each alloy concept. The pulsating load at the endurance limit was estimated for a failure probability of 50 percent. The low-cycle fatigue part of the S-N curve was supported by around 10 valid tests for each variant. The conversion of the pulsating load into the resulting tooth root stress was done as described in DIN 3990 Part 3 [5]. The allowable stress numbers for bending conditions $\sigma_{\mathrm{Flim}}$ and $\sigma_{\mathrm{FE}}$ given in DIN 3990/ISO $6336[5,6]$ are valid for standard reference test gears at standard test conditions in a gear running test and a failure probability of one percent. Therefore, the test results from the pulsator tests were converted to these conditions according to the state-of-the-art as outlined in detail by Niemann and Winter [31].

The results obtained from these tests are displayed in Table 5. Case carburized alloy Concept V1 (20MnCr5 mod.) exhibits a clearly higher tooth root bending strength than the case carburized 
alloy Concept V2 (20CrMo5 mod.), as can be expected from the hardness characteristics. It has been established that surface-hardened gears of high load capacity containing high residual compressive stresses in the surface layer due to shot peening exhibit an increased risk of crack initiation below the surface [32]. In this respect, the cleanness of the material has a decisive influence. Furthermore, it is assumed that the microstructure and especially the ductility of the surface layer are also relevant to the cracking behavior. Alloy Concept V1 did not show sub-surface crack initiation, which may be related to sufficiently high cleanness and ductility.

Figure 14a compares the determined allowable stress numbers to the tooth root bending stress levels according to DIN 3990/ISO 6336 [5,6] and to the test results of several batches of two case hardened Western European standard steels determined under comparable test conditions [33]. A further performance benchmark of both developed concepts against established case carburizing alloys is shown in Figure 14b. In this diagram, the grey shaded area indicates the typical performance range of European state-of-the-art carburizing grades (see also Figure 14a). Additionally, some international carburizing grades that were tested by the same method are indicated. Figure 14 clearly demonstrates that alloy Concept V1 ranks on top of quality level ME defined for established alloys according to DIN 3990 [5] and performs better than many higher alloyed steel grades including the reference grade 18CrNiMo7-6. Alloy Concept V2 compares well to the state-of-the-art alloys achieving quality level MQ.

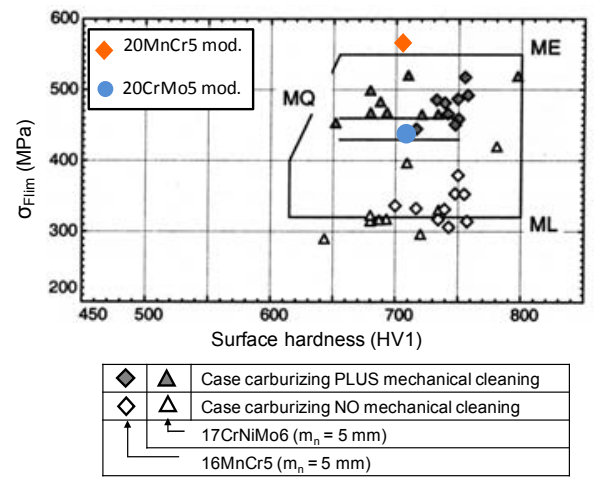

(a)

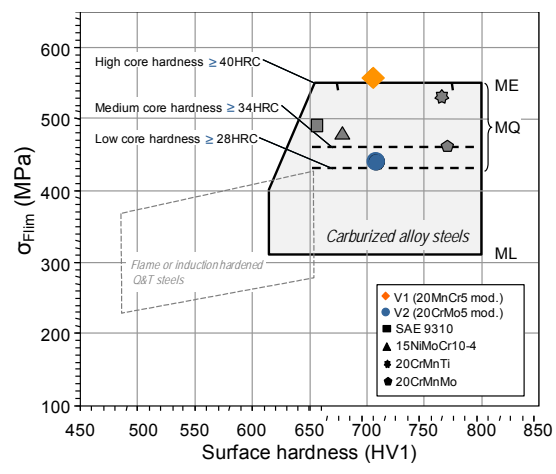

(b)

Figure 14. Comparison of the tooth root bending stress numbers of newly developed case carburized steels: (a) vs. strength levels of DIN 3990 and vs. the results of reference steels determined under comparable test conditions [30]; (b) vs. selected alternative case carburizing steels as specified in Table 1.

Table 5. Characteristics of the determined S-N-curves concerning tooth root bending strength for $50 \%$ failure probability, as well as nominal and allowable bending stress numbers.

\begin{tabular}{lcc}
\hline \multicolumn{1}{c}{ Criterion } & Concept V1 & Concept V2 \\
\hline $\begin{array}{l}\text { Nominal endurance tooth root bending stress for } \\
50 \% \text { failure probability }(\mathrm{MPa})\end{array}$ & 1368 & 1072 \\
\hline $\begin{array}{l}\text { Gradient of determined S-N curve at limited } \\
\text { fatigue life (50\% failure probability) }\end{array}$ & 28.1 & 8.8 \\
\hline $\begin{array}{l}\text { Number of load cycles at inflection point } \\
(50 \% \text { failure probability) }\end{array}$ & $2,048,078$ & 436,884 \\
\hline Allowable bending stress $\sigma_{\mathrm{FE}}(\mathrm{MPa})$ & 1134 & 885 \\
\hline Nominal bending stress $\sigma_{\mathrm{Flim}}(\mathrm{MPa})$ & 567 & 442 \\
\hline Cracking behavior in low-cycle fatigue range & $\begin{array}{l}\text { Fractures with crack } \\
\text { initiation at the surface }\end{array}$ & $\begin{array}{l}\text { Fractures with crack } \\
\text { initiation at the surface }\end{array}$ \\
\hline Cracking behavior in high-cycle fatigue range & $\begin{array}{l}\text { Fractures with crack } \\
\text { initiation at the surface }\end{array}$ & $\begin{array}{l}\text { Fractures with crack } \\
\text { initiation below the surface }\end{array}$ \\
\hline
\end{tabular}


In order to determine the pitting load capacity of the gear flank, repeated gear running tests were carried out for finding the endurance limit [33]. The endurance limit for pitting strength is considered to be reached when at least $50 \times 10^{6}$ load cycles are sustained without damage (this criterion is generally accepted by gear standards). The test rig was driven with a constant speed of $3000 \mathrm{rpm}$. All test runs were performed under oil spray lubrication (approximately $2 \mathrm{~L} / \mathrm{min}$ into the tooth mesh) with FVA (Forschungsvereinigung Antriebstechnik) Oil No. 3 with $4 \%$ additive Anglamol 99 (sulphur-phosphorous additive), a mineral oil of viscosity class ISO VG 100, and an oil temperature of $60^{\circ} \mathrm{C}$. Prior to each test run, a two-stage running-in period was performed.

Under the described test conditions, 6-8 test runs for each variant were scheduled at different load levels in order to determine the pitting load carrying capacity. The test runs were continued until either one of the failure criteria mentioned below was reached or the specified maximum number of load cycles was exceeded without failure. The test runs were regularly interrupted after a defined interval of load cycles in order to inspect the flank condition. According to the defined failure criteria, a test run was terminated when:

- Tooth breakage occurred;

- The flank area damaged by pitting exceeded about $4 \%$ of the working flank area of a single tooth or about $2 \%$ of the total working flank area;

- The mean profile deviation due to micropitting exceeded the limiting value of $15 \mu \mathrm{m}$ to $20 \mu \mathrm{m}$.

After every test run, the flank condition was evaluated and documented by means of digital photos (Figure 15). During all test runs of alloy Concept V2, micropitting was observed on the flanks of the test pinion and test gear. However, the limiting criterion of a profile deviation $f_{\mathrm{fm}}>20 \mu \mathrm{m}$ due to micropitting was not reached in any of the test runs. Normally, light micropitting leads to higher load cycles until a pitting failure occurs. Test gears made from alloy Concept V1 partly showed a significantly lower sensitivity to micropitting than the test gears made from alloy Concept V2.

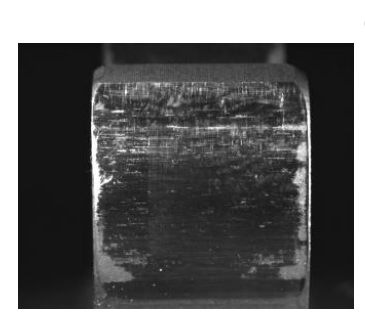

$\sigma \mathrm{H}_{0}=1598 \mathrm{~N} / \mathrm{mm}^{2}$ $51 \times 10^{6}$ load cycles

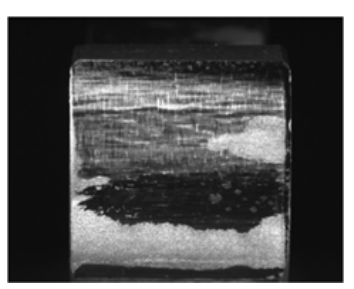

$\sigma \mathrm{H} 0=1495 \mathrm{~N} / \mathrm{mm}^{2}$, $51 \times 10^{6}$ load cycles

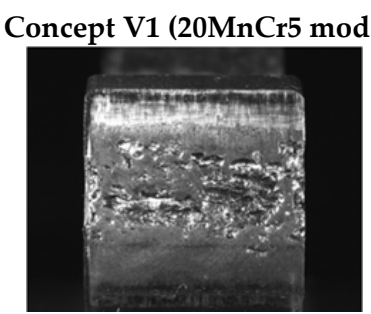

$\sigma \mathrm{H} 0=1801 \mathrm{~N} / \mathrm{mm}^{2}$, $15 \times 10^{6}$ load cycles Concept V2 (25CrMo5 mod.)

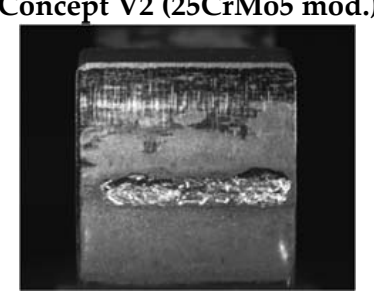

$\sigma_{\mathrm{H} 0}=1598 \mathrm{~N} / \mathrm{mm}^{2}$, $54 \times 10^{6}$ load cycles

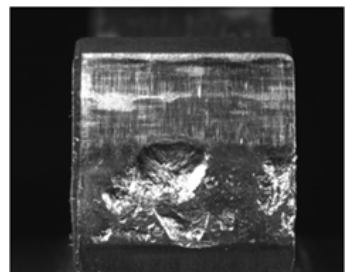

$\sigma \mathrm{H}_{0}=1900 \mathrm{~N} / \mathrm{mm}^{2}$, $9 \times 10^{6}$ load cycles

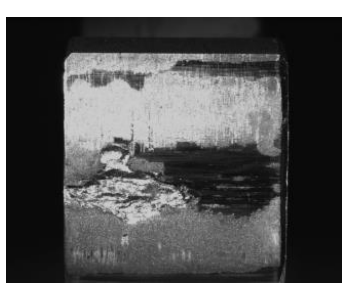

$\sigma_{\mathrm{H} 0}=1801 \mathrm{~N} / \mathrm{mm}^{2}$, $12 \times 10^{6}$ load cycles

Figure 15. Examples of the typical tooth flank condition at the end of the test runs for various nominal contact stresses and load cycles (tooth width is $14 \mathrm{~mm}$ ).

The performed gear running tests allow an approximate determination of the pinion torque at the endurance limit, as well as of the nominal contact stress number at the endurance for a failure probability of 50 percent. The allowable contact stress $\sigma_{\mathrm{Hlim}}$ representing the pitting load capacity with a failure probability of one percent is then calculated according to DIN 3990 [5]. Table 6 summarizes the determined flank pitting load capacity limits for the two developed steel grades. A benchmark 
comparison of these data against the strength values for the different quality levels according to DIN 3990/ISO 6336, as well as for some reference data from the literature [29] is provided by Figure 16. A further performance benchmark of both developed concepts against established case carburizing alloys is shown in Figure 17. Obviously, alloy Concept V1 (20MnCr5 mod.) exhibits a very high pitting endurance limit and outperforms established alloys of quality level ME. The pitting endurance limit of alloy Concept V2 (20CrMo5 mod.) is situated in the upper region of the established contact stress field for case hardened steels reaching quality level ME.

Table 6. Experimentally-determined endurance limit for pitting.

\begin{tabular}{ccc}
\hline Criterion & Concept V1 & Concept V2 \\
\hline Nominal endurance strength for 50\% failure probability $(\mathrm{MPa})$ & 1699 & 1547 \\
Allowable contact stress $(\mathrm{MPa})$ & 1793 & 1633 \\
\hline
\end{tabular}

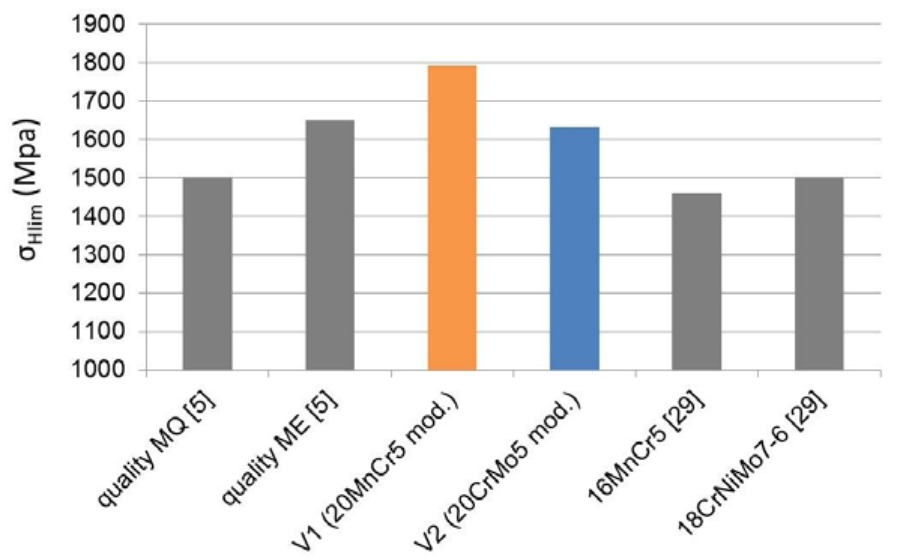

Figure 16. Comparison of the determined pitting strength number of newly developed case carburized steels vs. strength levels of DIN 3990 and literature data of reference steels.

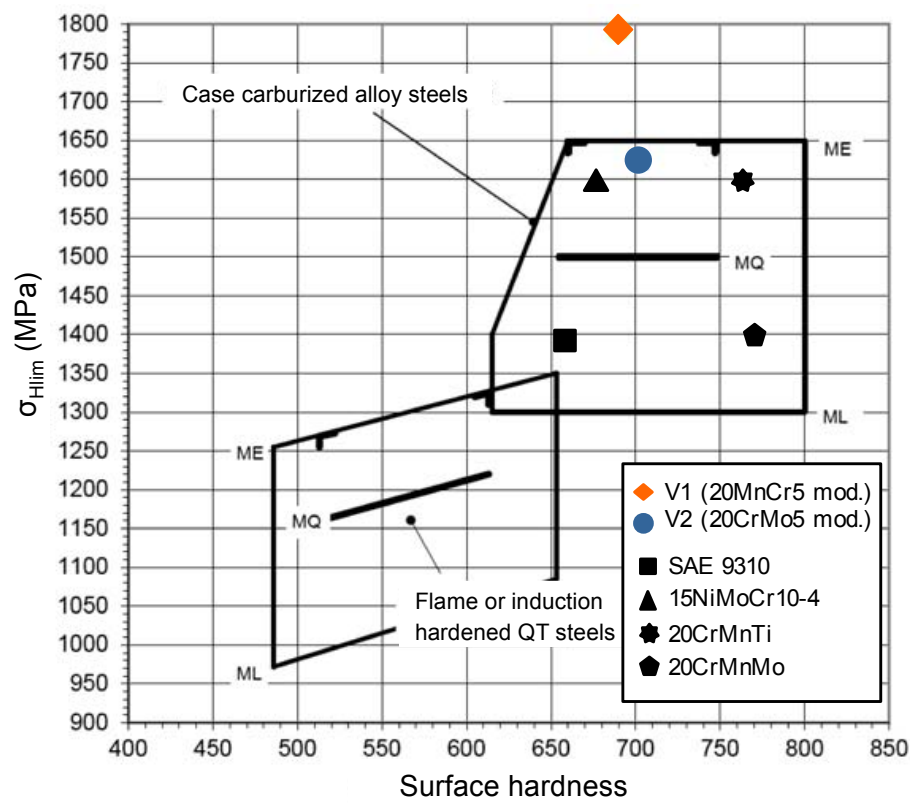

Figure 17. Comparison of the pitting endurance strength number of newly developed case carburized steels vs. strength levels of DIN 3990 and vs. selected alternative case carburizing steels as specified in Table 1. 
The current results suggest that alloy Concept V1 has the potential of providing an economically-viable solution for highly loaded gears in heavy machinery and vehicles. Its use in vehicle transmissions could enable downsizing of gear components, thereby reducing weight. In larger transmissions, such as those used in trucks and heavy machinery, its application can help with avoiding unexpected failure and extending warranty periods. The results of alloy Concept V2 indeed position it as a cost-attractive alternative to the established premium grade $18 \mathrm{CrNiMo7}-6$.

\section{Conclusions}

Many parameters such as material, heat treatment, gear design, machining and lubrication must be considered for optimizing gear box performance. This study identified the desired material characteristics with regard to two major fatigue failure mechanisms in gears, pitting and tooth root breakage, considering the particular stress conditions in large gears. The objective was to optimize the alloy composition of case carburizing steels for obtaining a load bearing characteristic providing better service performance of large gears. In the modified alloy design, particularly the dedicated use of molybdenum and niobium as alloying elements was considered.

Molybdenum alloying in case carburizing steels is established due to its pronounced hardenability effect. The current results demonstrate that molybdenum has several additional metallurgical benefits that are not provided by alternative hardenability elements:

- Molybdenum significantly increases the tempering resistance, thus opening an opportunity of performing secondary heat treatments after case carburizing. The increased tempering resistance also makes gears less vulnerable against hot running in case of lubrication problems during operation.

- It is also known that molybdenum enhances the large angle grain boundary cohesion, thus obstructing intergranular crack propagation and hence retarding macroscopic damage.

- Contrary to manganese, molybdenum does not have a strong segregation tendency, and it does not form inclusions. Furthermore, its use does not increase the sensitivity for intergranular oxidation, as is the case for manganese and chromium.

- The present investigation has demonstrated that modifying standard alloys with the moderate addition of molybdenum (0.5-0.7 wt \%) can lead to significantly better performance in gear running tests than state-of-the-art alloys including several steels highly alloyed with nickel.

Microalloy addition of niobium to case carburizing steels is an increasingly applied technology offering the following advantages:

- Niobium carbide nano-precipitates obstruct prior austenite grain coarsening during case carburizing and simultaneously reduce grain size scattering. A finer and more homogeneous grain structure results in improved toughness, higher fatigue resistance and less distortion after heat treatment.

- Niobium further increases the tempering resistance provided by molybdenum due to a metallurgical synergy based on solute drag and particle pinning.

- Prior austenite grain refinement of martensitic steels, as well as nano-carbide precipitates of niobium results in an increased resistance against hydrogen embrittlement.

The combined alloying effects of molybdenum and niobium are particularly relevant for highly loaded, large-sized gears requiring increased case hardening depth and thus long carburization times or elevated carburizing temperature. It was demonstrated by experimental benchmarking that the dedicated use of these metallurgical effects allows producing carburized gear steel with significantly increased performance in a cost-efficient way.

Acknowledgments: Part of this work has been financially supported by the International Molybdenum Association (IMOA), London, U.K. 
Author Contributions: Frank Hippenstiel designed and provided the steel alloys and forgings, Thomas Tobie designed and conducted the gear performance tests, Hardy Mohrbacher contributed to the metallurgical interpretation of the experimental results and wrote the paper.

Conflicts of Interest: The authors declare no conflict of interest. The founding sponsors had no role in the design of the study; in the collection, analyses, or interpretation of data; in the writing of the manuscript, and in the decision to publish the results.

\section{References}

1. Hippenstiel, F.; Johann, K.-P.; Caspari, R. Tailor Made Carburizing Steels for Use in Power Generation Plants. In Proceedings of the International European Conference on Heat Treatment, Strasbourg, France, June 2009.

2. Spitzer, H.; Bleck, W.; Flesch, R. Einsatzstähle-Normung und Entwicklungstendenzen, ATTT/AWT-Tagung Einsatzhärtung; Tagungsband; Hanser: München, Germany, 1998; pp. 11-20.

3. N.N. DIN EN 10084:2008. Carburizing Steels; Beuth Verlag: Berlin, Germany, 2008.

4. $\quad$ N.N. ISO 683-11: Edition 1987. Heat-Treatable Steels, Alloy Steels and Free-Cutting Steels, Part 11: Wrought Case-Hardening Steels; Beuth Verlag: Berlin, Germany, 1981.

5. $\quad$ N.N. DIN 3990 1-5: Edition 1987:12. Calculation of Load Capacity of Cylindrical Gears; Endurance Limits and Material Qualities; Beuth Verlag: Berlin, Germany, 1987.

6. N.N. ISO 6336 1-5: Edition 2006/2003. Calculation of Load Capacity of Spur and Helical Gears-Strength and Quality of Materials; Beuth Verlag: Berlin, Germany, 2003.

7. Tobie, T.; Höhn, B.-R.; Stahl, K. Tooth flank breakage-Influences on subsurface initiated fatigue failures of case hardened gears. In Proceedings of the ASME 2013 International Design Engineering Technical Conferences and Computers and Information in Engineering Conference, IDETC/CIE 2013, DETC2013-12183, Portland, OR, USA, 4-7 August 2013.

8. Tobie, Th. Zur Grübchen - und Zahnfußtragfähigkeit einsatzgehärteter Zahnräder. Ph.D. Thesis, Technical University of Munich, Munich, Germany, 2001.

9. Steutzger, M. Größeneinfluß auf die Zahnfußfestigkeit, Forschungsvereinigung Antriebstechnik e.V., Frankfurt am Main, Forschungsvorhaben Nr. 162, Heft 529. 1997.

10. Uno, M.; Hirai, M.; Nakasato, F. Effect of Alloying Elements on the Properties of Cr-free Carburizing Steels. Sumitomo Search 1989, 39, 33-44.

11. Wang, C.; Wang, M.; Shi, J.; Hui, W.; Dong, H. Effect of Microstructure Refinement on the Strength and Toughness of Low Alloy Martensitic Steel. J. Mater. Sci. Technol. 2007, 23, 659-664.

12. Morito, S.; Saito, H.; Ogawa, T.; Furuhara, T.; Maki, T. Effect of Austenite Grain Size on the Morphology and Crystallography of Lath Martensite in Low Carbon Steels. ISIJ Int. 2005, 45, 91-94. [CrossRef]

13. Huchtemann, B.; Schüler, V. Beitrag zur Beeinflussung der Austenitkorngröße von Edelbaustahlen. HTM 1993, 48, 124-132.

14. Kubota, M.; Ochi, T. Development of Anti-Coarsening Steel for Carburizing. Mater. Sci. Forum 2007, 539-543, 4855-4860. [CrossRef]

15. Leap, M.J.; Brown, E.L. Effects of composition and, processing on development of grain coarsening resistance in cold forged and carburised steel. Mater. Sci. Technol. 2002, 18, 945-958. [CrossRef]

16. Kimura, T.; Kurebayashi, Y. Niobium in Microalloyed Engineering Steels, Wire Rods and Case Carburized Products. In Proceedings of the 2001 International Symposium on Niobium, TMS 2001, Orlando, FL, USA, 2-5 December 2001; pp. 801-820.

17. Hippenstiel, F. Tailored Solutions in Microalloyed Engineering Steels for the Power Transmission Industry. Mater. Sci. Forum 2007, 539-543, 4131-4136. [CrossRef]

18. Alogab, K.A.; Matlock, D.K.; Speer, J.G.; Kleebe, H.J. The Influence of Niobium Microalloying on Austenite Grain Coarsening Behavior of Ti-modified SAE 8620 Steel. ISIJ Int. 2007, 47, 307-316. [CrossRef]

19. Alogab, K.A.; Matlock, D.K.; Speer, J.G.; Kleebe, H.J. The Effects of Heating Rate on Austenite Grain Growth in a Ti-modified SAE 8620 Steel with Controlled Niobium Additions. ISIJ Int. 2007, 47, 1034-1041. [CrossRef]

20. Klenke, K.; Kohlmann, R.; Reinhold, P.; Schweinebraten, W. Improved Performance by High Temperature Carburizing Shown by the Example of VW4521 + Nb, Proceedings Steels in Cars and Truck 2008; Verlag Stahleisen Düsseldorf: Düsseldorf, Germany, 2008; pp. 173-183.

21. Hong-Seok, Y.; Bhadeshia, H.K.D.H. Austenite Grain Size andthe Martensite-Start Temperature. Scr. Mater. 2009, 60, 493-495. 
22. Randak, A.; Eberbach, R. Einfluß der Austenitkorngröße auf einige Eigenschaften des Stahls $16 \mathrm{MnCr} 5$. HTM Härterei-Technische Mitteilungen 1969, 24 Heft 3, 201-209.

23. Dehner, E.; Weber, F. Experience with Large high-Speed Load Gears. GearTechnology 2007, July, 42-52.

24. Togashi, F.; Nishizawa, T. Effect of Alloying Elements on the Mobility of Ferrite/Austenite Interface. J. Jpn. Inst. Met. 1976, 40, 12-21. [CrossRef]

25. Tanaka, T.; Enami, T. Metallurgical Variables Involved in Controlled Rolling of High Tensile Steels and Its Application. Tetsu-to-Hagané 1972, 58, 1775-1790. [CrossRef]

26. Pavlina, E.J.; Speer, J.G.; Van Tyne, C.J. Equilibrium solubility products of molybdenum carbide and tungsten carbide in iron. Scr. Mater. 2012, 66, 243-246. [CrossRef]

27. Lakshmanan, V.K.; Kirkaldy, J.S. Solubility Product for Niobium Carbide in Austenite. Metall. Trans. A 1984, 15, 541-553. [CrossRef]

28. Koyama, S.; Ishii, T.; Narita, K. Effects of Mn, Si, Cr, and Ni on the Solution and Precipitation of Niobium Carbide in Iron Austenite. J. Jpn. Inst. Met. 1971, 35, 1089-1094. [CrossRef]

29. N.N. ISO 14635 Part 1: Gears_FZG Test Procedures_Part 1: FZG Test Method A/8,3/90 for Relative Scuffing Load-Carrying Capacity of Oil; International Organization for Standardization: Geneva, Switzerland, 2000.

30. Weigand, U. Werkstoff- und Wärmebehandlungseinflüsse auf die Zahnfußtragfähigkeit. Ph.D. Thesis, Technical University of Munich, Munich, Germany, 1999.

31. Niemann, G.; Winter, H. Maschinenelemente, Band II: Getriebe Allgemein, Zahnradgetriebe-Grundlagen, Stirnradgetriebe; Springer: Berlin, Germany, 1989.

32. Bretl, N.; Schurer, S.; Tobie, T.; Stahl, K.; Höhn, B.-R. Resistenza a flessione-Al piede dei denti di ingranaggi cementati. Organi di Trasmissione 2014, 3, 28-32.

33. Höhn, B.-R.; Stahl, K.; Schudy, J.; Tobie, Th.; Zornek, B. FZG Rig-Based Testing of Flank Load-Carrying Capacity Internal Gears. GearTechnology 2012, June/July, 60-69.

(C) 2017 by the authors. Licensee MDPI, Basel, Switzerland. This article is an open access article distributed under the terms and conditions of the Creative Commons Attribution (CC BY) license (http://creativecommons.org/licenses/by/4.0/). 